\title{
Tratamento de efluente de refinaria de óleo de soja por sistema de flotação por ar dissolvido ${ }^{1}$
}

\author{
Juliana Cecchet ${ }^{2}$, Benedito M. Gomes ${ }^{2}$, Ricardo N. Costanzi ${ }^{2} \&$ Simone D. G omes ${ }^{2}$
}

\begin{abstract}
RESUMO
Propôs-se, neste trabal ho, avaliar o desempenho de coagulantes combinados a três tipos de polieletrólitos (aniônico, cationnico e não iônico), através de Flotação por Ar Dissolvido (FAD), no tratamento de efluentes de refinaria de óleo de soja. 0 experimento, conduzido em escala de laboratório, ensejou não apenas encontrar, pelos diagramas de coagulação, a melhor faixa de pH e a melhor concentração de coagulante mas, também, as dosagens e os tipos de floculante, culminando em sua dosagem ótima. Para tanto, parâmetros, como tempo e gradiente de mistura rápida $\left(1 \mathrm{~min} / 150 \mathrm{~s}^{-1}\right)$, tempo e gradiente de mistura lenta (10 min / $\left.40 \mathrm{~s}^{-1}-5 \mathrm{~min} / 20 \mathrm{~s}^{-1}\right)$, pressão na câmara de saturação (450 $\left.\mathrm{kPa}\right)$ e velocidade ascensional $\left(1,67 \mathrm{~cm} \mathrm{~min}^{-1}\right)$ foram usados para a fase da flotação nos ensaios. Após o término dos ensaios, amostras do efluente tratado foram utilizadas para comparativo com o efluente bruto, obtendo-se um grau de remoção de demanda química de oxigênio (DQ 0) de 93,7 e 95,1\% e de óleos e graxas (O\&G) de 94,2 e 99,8\% para os ensai os 1 e2, respectivamente. Apesar de sua excelente eficiência de remoção, 0 efluente tratado não apresentou características de reúso em torres de resfriamento, haja vista que sua DQ 0 ficou muito acima de $75 \mathrm{mg} \mathrm{L}^{-1} \mathrm{O}_{2}$.
\end{abstract}

Palavras-chave: coagulação, floculação, FAD, polieletrólito

\section{Treatment of efluents of soybean oil refnery by dissolved air flotation}

\begin{abstract}
The aim of this work was to evaluate the performance of coagulants combined with three polyelectrolytes (anionic, cationic and non ionic) using dissolved air flotation (DAF) in the treatment of effluents of the soybean oil refinery. This study was conducted at laboratory-scale to find, through the coagulation diagram, the best limits of pH and coagulant concentration. With those limits, the dosage of flocculants was varied to achieve the optimum dosage. For that, some parameters were fixed: time and rapid mix gradient ( 1 min and $150 \mathrm{~s}^{-1}$ ), time and slow mix gradient (10 min and $40 \mathrm{~s}^{-1}-5 \mathrm{~min}$ and $20 \mathrm{~s}^{-1}$ ), pressure in saturation chamber $(450 \mathrm{kPa})$ and ascension velocity $\left(1.67 \mathrm{~cm} \mathrm{~min}^{-1}\right)$ for two flotation tests. After the flotation tests, samples of treated effluent were collected for comparison with crude effluent. The removal percentage obtained of chemical oxygen demand (COD) was 93.7 and $95.1 \%$ and of oil and greases $(O \& G)$ was 94.2 and $99.8 \%$ for the test 1 and 2, respectively. Despite excellent efficiencies of removal, the treated effluent did not present characteristics for reuse in cooling towers, because the COD was above $75 \mathrm{mg} \mathrm{L}^{-1} \mathrm{O}_{2}$.
\end{abstract}

Key words: coagulation, flocculation, DAF, polyelectrolyte

1 Parte da Dissertação de Mestrado do primeiro autor, apresentada à UNIOESTE

2 RHESA/U N IOESTE, Rua Universitária 2069, CEP 85819-110, Cascavel, PR. Fone: (45) 3220-3000. E-mail: juliana.cecchet@gmail.com; bmgomes@unioeste.br; ricardocostanzi@gmail.com; simoned@unioeste.br 


\section{INTRODUÇãO}

O efluente gerado no processo de industrialização do óleo de soja possui alta concentração de demanda química de oxigênio (DQO), sólidos suspensos totais (SST) e dissolvidos (SSD), óleos e graxas, dentre outros componentes orgânicos. Portanto, pode causar impactos significativos se descartado em sua forma bruta no meio ambiente (Alther, 2008; Yang, 2007).

Essa é a razão do porquê se deve escolher um sistema de tratamento adequado, no qual se possa levar em consideração os tipos e concentração de contaminantes presentes no efluente, a qualidade necessária do efluente após o tratamento, a vazão a ser tratada, os métodos e opções que possuam análise custo/benefício adequados ao contexto brasileiro. Desta forma, faz-se necessário uma análise do sistema de produção associado ao sistema de tratamento.

No processo de refino de óleo existem três fases: a neutralização, o branqueamento e a desodorização. De acordo com Willey (2001), as maiores fontes de geração de efluentes do processo de refino de óleo são: o processo da quebra das cadeias de sabões na neutralização com geração de águas ácidas; o poço barométrico da desodorização e outros sistemas de vácuo; e a lavagem de pisos, terra de branqueamento, condensados e drenagem de tanques.

$\mathrm{O}$ efluente gerado no processo de refino está em forma de emulsão óleo/água. As gotas de óleo estabilizadas quimicamente, segundo Lelinski (1993), se comportam mais como partículas sólidas que as estabilizadas fisicamente, devido à sua alta densidade de carga superficial e ao tamanho reduzido. Vários autores, entre eles Lelinski (1993), têm constatado que as gotículas de óleo apresentam carga superficial negativa para uma ampla faixa de $\mathrm{pH}$ (freqüentemente a partir de $\mathrm{pH}$ maior que 3 ).

Para que as operações de coagulação, floculação e flotação ocorram, é conveniente promover a desestabilização da emulsão pela neutralização da superfície carregada eletricamente. A presença de cargas elétricas aumenta a repulsão entre as partículas, dificultando a aglomeração e a formação de agregados maiores e de mais fácil sedimentação. $\mathrm{O}$ fenômeno de neutralização consiste exatamente na eliminação dessas cargas eletrostáticas superficiais, ou seja, na diminuição do potencial Zeta (Al-Shamrani et al., 2002).

De acordo com Yianatos (2007), as cargas elétricas das partículas e das bolhas são fatores muito importantes na flotação por ar dissolvido (FAD). O pré-tratamento químico é um requisito essencial para a alta eficiência da FAD; em geral, são necessários gradientes de velocidades altas durante a dosagem química (mistura rápida) e baixas para promover a agregação das partículas durante a floculação (Bing et al., 2007).

O processo de FAD unido a uma etapa prévia de coagulação/floculação, é capaz de promover remoções de $\mathrm{DBO}_{5,20}$ superiores a 95\%; o teor de óleos e graxas é reduzido para concentrações menores que $50 \mathrm{mg} \mathrm{L}^{-1}$ (Bensadok et al., 2007). Esta é a tecnologia de flotação mais recomendada porque minimiza a ruptura dos flocos formados na etapa de coagulação/floculação (Zheng et al., 2006; Yianatos \& Henríquez, 2007).
As bolhas de gás são obtidas por meio da liberação da parcela de gás previamente dissolvida na massa líquida, em virtude da queda de pressão na entrada do tanque de flotação.

Azbar \& Yonar (2004) fizeram uma avaliação comparativa em escala de laboratório e em escala industrial de alternativas para tratamento de efluente proveniente de refinaria de óleo de vegetal, dentre elas o tratamento físico-químico por coagulação, seguido de floculação e flotação por ar dissolvido (FAD).

O experimento de coagulação foi realizado com o uso de sulfato de alumínio e cloreto férrico obtendo-se uma dosagem ótima de $250 \mathrm{mg} \mathrm{L}^{-1}$. FAD foi aplicada obtendo-se uma remoção de DQO de $84 \%$, óleos e graxas de $83 \%$ e de SST de $81 \%$ com a aplicação do sulfato de alumínio, e de $81 \%$ de DQO, $73 \%$ de óleos e graxas e $78 \%$ de SST para cloreto férrico (Azbar \& Yonar, 2004).

Objetivou-se, neste estudo, avaliar dois coagulantes combinados a três classes de polieletrólitos (aniônico, catiônico e não iônico), associados à técnica de FAD, a fim de viabilizar seu uso em tratamento de efluentes de refinaria de óleo de soja e avaliar a possibilidade de reúso da água tratada em torres de resfriamento no processo de industrialização, em que um dos parâmetros de controle é a DQO de no máximo $75 \mathrm{mg} \mathrm{L}^{-1}$.

\section{MATERIAL E MÉTODOS}

A pesquisa foi realizada em escala de bancada visando aplicar os resultados em uma unidade de tratamento físicoquímico com flotação por ar dissolvido, em escala industrial.

Os produtos químicos utilizados para coagulação, foram o Klaraid PC 2700 (clorhidrato de álcool amino) de origem orgânica, e o BetzDearborn PE 019 (poliamina em meio ácido) de origem combinada orgânica e inorgânica fornecido pela GE Infrastructure e preparado em solução com concentração de $100 \mathrm{mg} \mathrm{L}^{-1}$; para floculação foram utilizados 3 tipos de floculantes, BetzDearborn F 11 (aniônico) e Polyfloc CE 1161 fornecidos prela GE Infrastructure e um floculante não iônico, cedido pela Kurita. Todos os floculantes foram preparados em solução com concentração de $1 \mathrm{mg} \mathrm{L}^{-1}$.

Realizou-se a coleta das amostras em uma indústria de refino de óleo de soja, na qual o efluente fica armazenado em tanques de equalização que possuem sistema de circulação para homogeneização; esta coleta se deu por meio de uma válvula situada na parte inferior dos tanques enquanto o efluente bruto foi acondicionado em galão de $50 \mathrm{~L}$, sem passagem de luz.

Os ensaios de coagulação, floculação e flotação, foram realizados em uma unidade de flotação por ar dissolvido, em escala de bancada por batelada. O equipamento Flotateste é constituído de uma câmara de pressurização, 3 jarros para coagulação-floculação-flotação e um conjunto motor-agitador.

A câmara de saturação e os jarros foram construídos com base em Centurione Filho \& Di Bernardo (2003). A operação do equipamento foi realizada da seguinte maneira (Figura 1).

Passo 1: Encher a câmara com água, mantendo-se os registros (7) e (8) abertos e os registros (4), (5) e (6) fechados. 


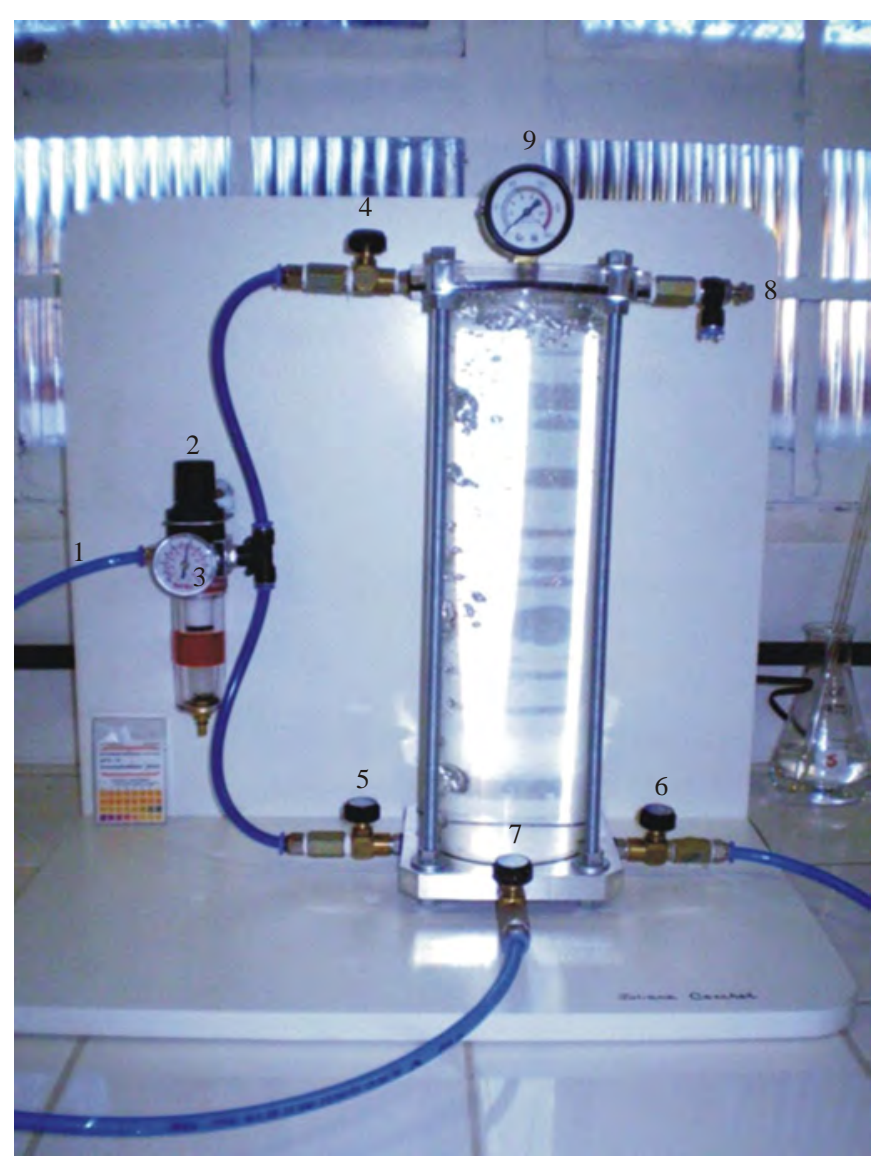

Figura 1. Esquema da câmara de saturação - Legenda: (1) Entrada de ar, (2) Registro do filtro de ar, (3 e 9) Manômetro, $(4,5,6,7)$ Registro tipo agulha, (8) Registro de saída de ar

Quando o nível de água na câmara for suficiente para a execução do ensaio programado, fechar os registros (7) e (8).

Passo 2: Ligar o compressor de ar e regular a pressão pouco acima da desejada na câmara de saturação utilizando-se o registro (2) e o manômetro (3); para isto, é necessário girar o registro (2) no sentido horário e, para mantê-lo inalterado, basta deslocá-lo para baixo;

Passo 3: Abrir, gradativa e totalmente, o registro (5); para atingir a pressão desejada no interior da câmara, utilizar o registro (8) para um ajuste mais preciso e o manômetro (9) para saturar a água pelo tempo desejado (aproximadamente $10 \mathrm{~min}$ );

Passo 4: Fechar simultaneamente os registros (5) e (8) ao final do tempo de saturação;

Passo 5: Depois de bem homogeneizado, adicionar o efluente aos jarros de forma que os dois litros de cada jarro sejam completados 4 ou 5 vezes alternadamente; este procedimento tem, como finalidade a obtenção de maior homogeneidade no conteúdo nos jarros.

Passo 6: É extremamente importante eliminar bolhas e pequenas bolsas de ar que possam existir na base do jarro de flotação, pois a sua permanência afetaria a distribuição da água saturada com o ar, durante a recirculação; isto pode ser feito inclinando-se o jarro para frente e para trás.

Passo 7: Acertar o $\mathrm{pH}$ do efluente nos jarros, conforme desejado, com auxílio do pHmetro devidamente calibrado.

Passo 8: Conectar os tubos de condução e distribuição de água saturada com o ar;

Passo 9: Programar o aparelho para o tempo de mistura rápida de $1 \mathrm{~min}$, com um gradiente de $150 \mathrm{~s}^{-1}$ e tempo de floculação de $10 \mathrm{~min}$, com um gradiente de $40 \mathrm{~s}^{-1} \mathrm{e}$, posteriormente, 5 min com um gradiente de $20 \mathrm{~s}^{-1}$.

Passo 10: Dosar o coagulante e o floculante nos recipientes apropriados localizados na parte frontal do equipamento;

Passo 11: Acionar o equipamento e adicionar o coagulante e o floculante ao processo.

Passo 12: Após o fim da agitação, abrir os registros (4) e (6). O registro (4) tem como função manter a pressão inalterada no interior da câmara durante a recirculação da água saturada. Abrir os registros dos jarros de flotação imediatamente (primeiro o do meio e em seguida as laterais) para a aplicação da água de recirculação com a taxa (R) prevista. Terminada a recirculação, fechar as válvulas e acionar o cronômetro; a quantidade de água de recirculação a ser introduzida em um jarro é calculada em função do volume do jarro;

Passo 13: Descartar a água durante $2 \mathrm{~s}$ e iniciar a coleta das amostras utilizando-se béqueres para o tempo correspondente às velocidades ascensionais desejadas. No ensaio de flotação o ponto de coleta está situado a $5,25 \mathrm{~cm}$ do fundo do jarro; assim, o tempo de coleta $(t, \min )$ corresponde às taxas de flotação.

Como o tempo de coleta de amostra de água flotada deve ser de $20 \mathrm{~s}$, inicia-se a coleta com 4 min e 33 s terminandoa em 4 min e $53 \mathrm{~s}$.

Passo 14: Efetuar a leitura dos parâmetros (turbidez e cor aparente) e preservar as amostras.

Para a realização dos ensaios fixaram-se os parâmetros de tempo de mistura rápida (Tmr) em $1 \mathrm{~min}$, gradiente de mistura rápida $(\mathrm{Gmr})$ em $150 \mathrm{~s}^{-1}$, tempo de floculação $\left(\mathrm{Tf}_{1} \mathrm{e}\right.$ $\left.\mathrm{Tf}_{2}\right)$ em 10 e 15 min, gradiente de floculação $\left(\mathrm{Gf}_{1}\right.$ e $\left.\mathrm{Gf}_{2}\right)$ em 40 e $20 \mathrm{~s}^{-1}$, pressão na câmara de saturação em $450 \mathrm{kPa}$, taxa de recirculação em $30 \%$ e velocidade ascensional de $1,67 \mathrm{~cm} \mathrm{~min}^{-1}$, sendo estes dois últimos parâmetros encontrados por ensaios preliminares e os demais por aproximação obtida em estações de tratamento de efluentes. As variações das concentrações dos coagulantes foram feitas na faixa de 400 a $600 \mathrm{mg} \mathrm{L}^{-1}$, dos floculantes na faixa de 2 a $11 \mathrm{mg} \mathrm{L}^{-1}$ e nas faixas de $\mathrm{pH}$ de 3 a 6 .

O efluente foi caracterizado em seu estado bruto e após os ensaios de Flotateste para a observação das eficiências de remoção. Os parâmetros analisados para a caracterização do efluente bruto foram: substâncias solúveis em hexano (SSH), sólidos suspensos totais (SST), sólidos suspensos voláteis (SSV), demanda química de oxigênio (DQO), alcalinidade total (AT), turbidez, temperatura e $\mathrm{pH}$. As metodologias de análise utilizadas estão descritas no Standard Methods for the Examination of Water and Wastewater (Clesceri et al., 1998).

\section{RESULTADOS E DISCUSSÃO}

Após vários ensaios efetuando variação no $\mathrm{pH}$ e variando a concentração dos coagulantes em 400 a $600 \mathrm{mg} \mathrm{L}^{-1}$, obtiveram-se os diagramas de coagulação ilustrado na Figura 2A e 2B. 
A.

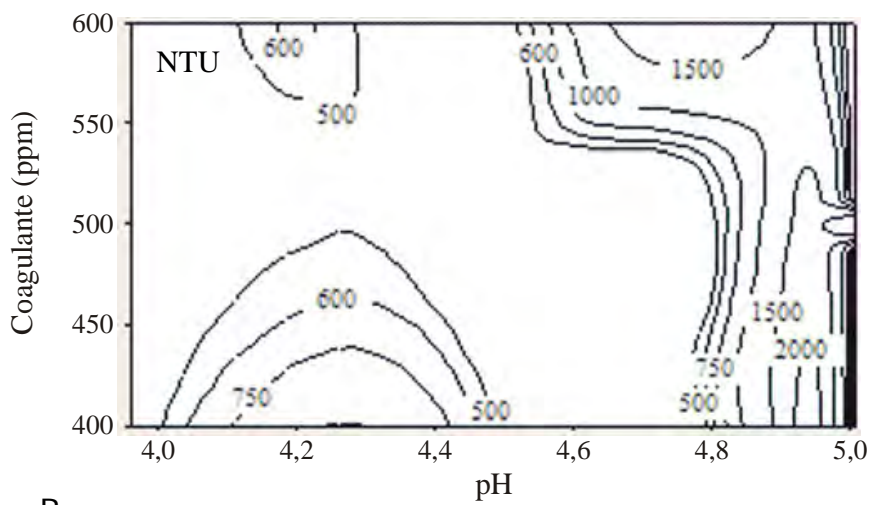

B.

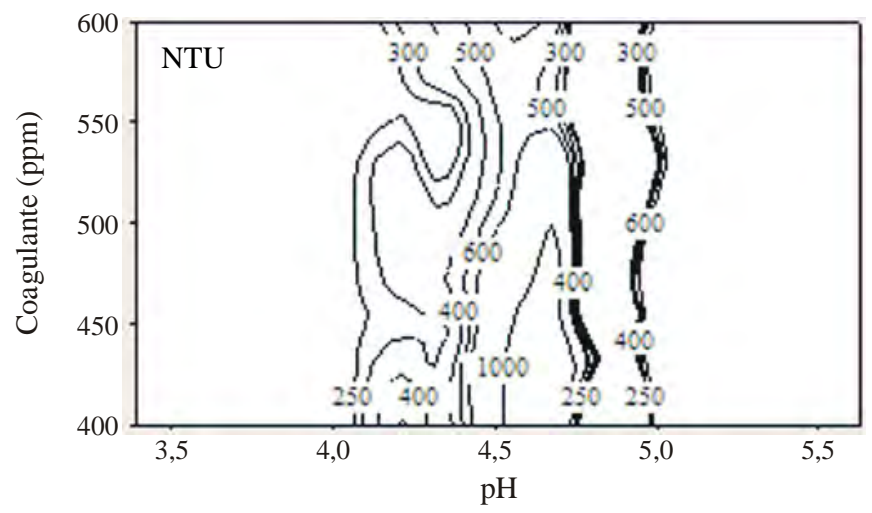

Figura 2. Diagrama de coagulação para efluente de refino de óleo de soja. (A) Turbidez remanescente, em função da dosagem do coagulante PE 019 e $\mathrm{pH}$ corrigido, $\mathrm{Va}=1,67 \mathrm{~cm} \mathrm{~min}^{-1}$. Turbidez inicial da água bruta $=$ 33700 NTU (B) Turbidez remanescente, em função da dosagem do coagulante PC 2700 e pH corrigido, $\mathrm{Va}=1,67 \mathrm{~cm} \mathrm{~min}^{-1}$. Turbidez inicial da água bruta $=36800$ NTU

A região demarcada com 500 NTU, na Figura 2A, demonstra a região central ótima de coagulação compreendida para uma dosagem de PE 019 de 500 a $550 \mathrm{mg} \mathrm{L}^{-1}$ e valores de $\mathrm{pH}$ entre 4,0 e 4,5 (Ahmad et al., 2006); nela, podem ser verificados valores de turbidez abaixo de 500 NTU, indicando uma eficiência de remoção em torno de 98,8\%; para o PC 2700. Conforme a Figura 2B, a dosagem foi de 400 a $600 \mathrm{mg} \mathrm{L}^{-1} \mathrm{e}$ valores de $\mathrm{pH}$ entre 3,4 e 4,0, próximo de Zhi et al. (2009) e diferente de Zeng et al. (2007). Verificam-se nesta região, valores de turbidez abaixo de 250 NTU, apresentando uma eficiência de remoção de $99,6 \%$.

Todos os coagulantes utilizados são catiônicos e apresentaram boa eficiência na remoção da turbidez e da cor aparente, confirmando o que foi relatado por Lelinski (1993).

Para efeito de otimização do sistema em relação ao $\mathrm{pH}$, se adotou como a melhor dosagem o coagulante PE 019, ou seja, com concentração de $500 \mathrm{mg} \mathrm{L}^{-1}$ de DQO e pH de 4,5. Os referidos parâmetros foram fixados como ótimos, ocorrendo variação de dosagens de floculantes, conforme apresentado na Figura 3A, caso em que o floculante F11 apresentou melhores resultados em comparação com os outros dois, sendo sua dosagem ótima de $4 \mathrm{mg} \mathrm{L}^{-1}$. Observa-se que, quanto maior a dosagem, maior também, o grau de turbidez da água.

Nota-se, na Figura 3B, que a inserção dos floculantes não iônicos e CE 1161 no processo fazem aumentar consideravelmente os valores de turbidez das amostras; já o floculante

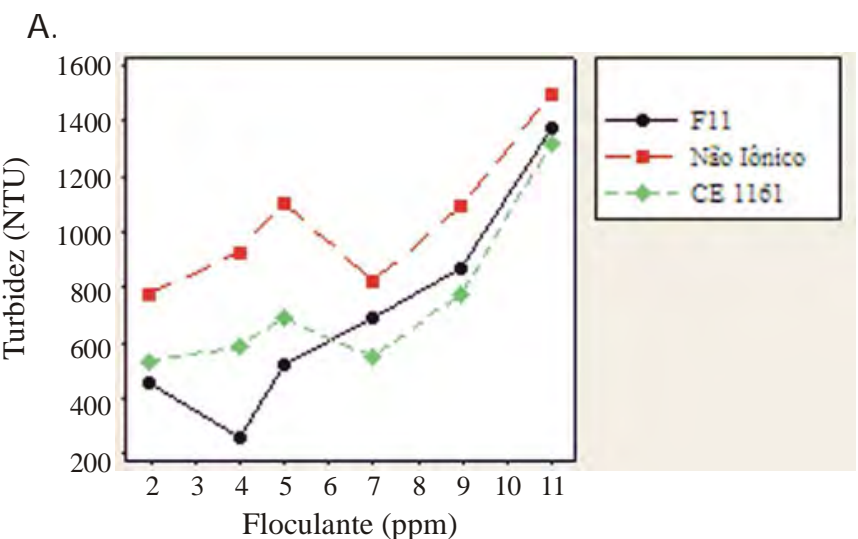

B.

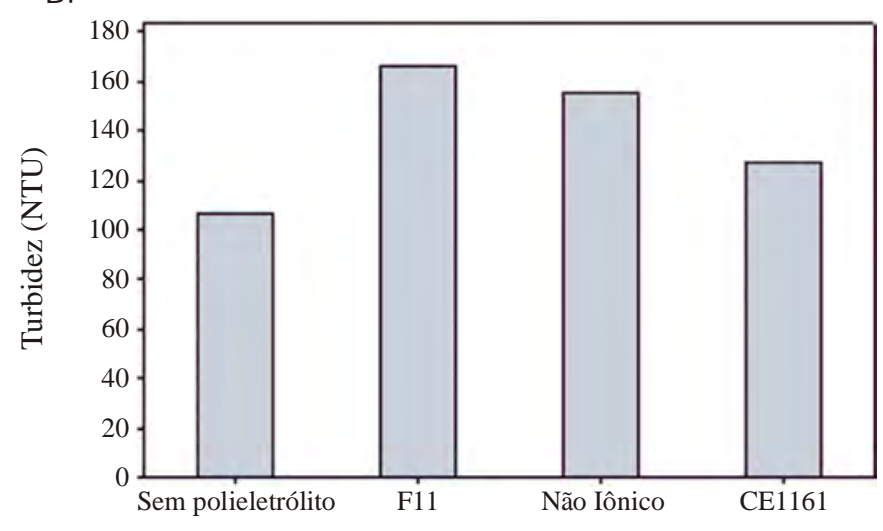

C.
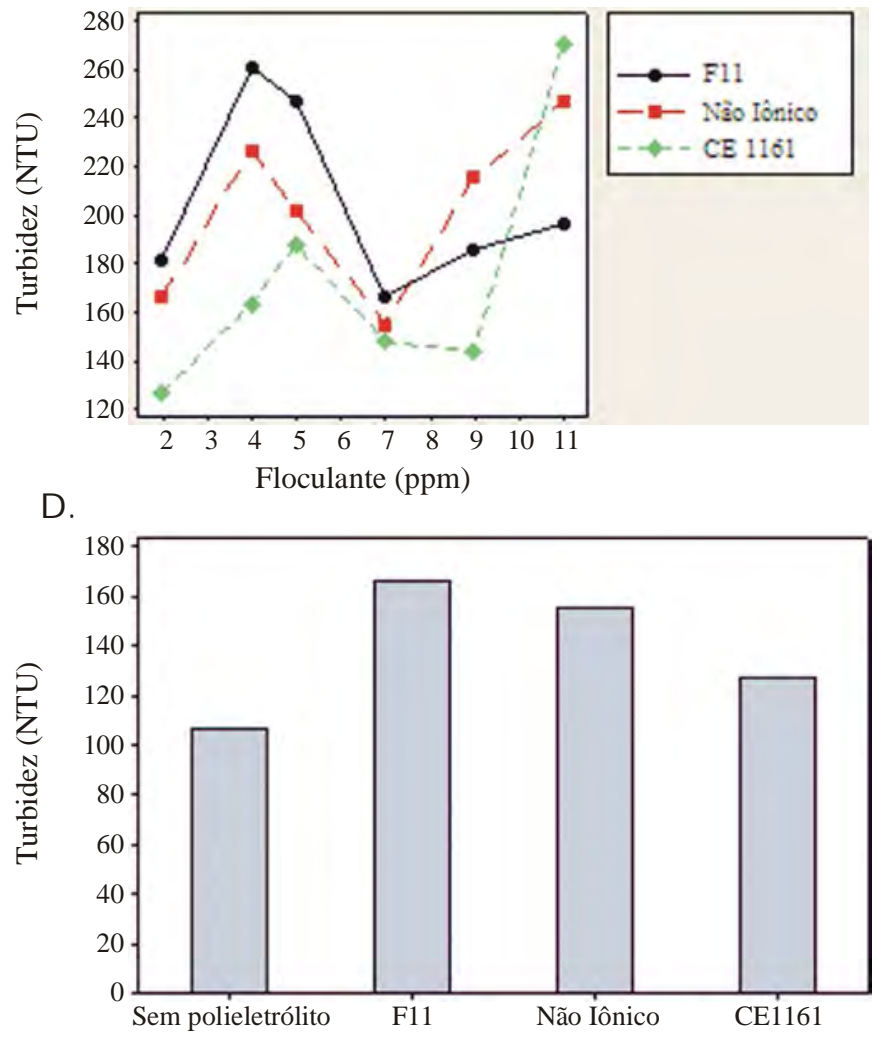

Figura 3. Comparativo de eficiência de remoção de turbidez (A) Dosagem fixa de PE 019 com $500 \mathrm{mg} \mathrm{L}^{-1}$ de DQ 0 e pH de 4,5 (B) entre os melhores resultados obtidos com os diferentes polieletrólitos e efluente tratado sem adição de polieletrólito, para o ensaio com o PE 019 (C) Dosagem fixa de PC 2700 em $600 \mathrm{mg} \mathrm{L}^{-1}$ e pH de 4,0 (D) entre os melhores resultados obtidos com os diferentes polieletrólitos e efluente tratado sem adição de polieletrólito para o ensaio com o PC 2700 
F11 mostrou-se ligeiramente mais eficiente na remoção da turbidez em relação à amostra tratada apenas com o coagulante PE 019.

Da mesma forma que para o coagulante PC 2700, na concentração de $600 \mathrm{mg} \mathrm{L}^{-1}$ e pH de 4,0 variaram as dosagens de floculantes, conforme a Figura 3C. Nesta bateria de ensaios, os três floculantes indicaram a mesma concentração ótima de floculação; os valores de turbidez, também, se aproximaram muito, variando entre 148 a 166 NTU. A Figura 3C mostra picos de elevação de turbidez entre as concentrações ótimas, deixando bem evidente a faixa de concentração na qual os polieletrólitos atuam com mais eficiência.

A escolha do polieletrólito não iônico como "ótimo", apesar de não apresentar a menor turbidez, se deu em relação à remoção da cor.

$\mathrm{Na}$ Figura 3D, tem-se que a inserção dos floculantes no processo acarretou no aumento dos valores de turbidez nas amostras em comparação com a amostra tratada apenas com coagulante PC 2700.

Constatou-se, através dessas comparações, que os polieletrólitos possuem pequena faixa de atuação, conferindo aumento de turbidez na amostra tratada em relação à tratada apenas com o coagulante, salvo o caso do efluente tratado com o PE 019, juntamente com o F11.

Conferindo o que foi estudado por vários autores, entre eles Hami et al. (2007), observou-se que a baixa concentração de floculante ( 3 a $15 \mathrm{mg} \mathrm{L}^{-1}$ ) causa efeitos positivos na eficiência de remoção enquanto o uso de quantidades excessivas diminui a eficiência do processo na flotação.

A Tabela 1 mostra os resultados, em termos de remoção de turbidez, SST, SSV, O\&G e DQO do efluente bruto, em relação ao efluente tratado com os parâmetros otimizados obtidos.

Tabela 1. Caracterização do efluente bruto, tratado e \% de remoção para a 1 a bateria de ensaios com PE 019 e F11 e 20 bateria de ensaios com PC 2700 e não iônico

\begin{tabular}{|c|c|c|c|c|c|c|}
\hline \multirow{3}{*}{$\begin{array}{l}\text { Variáveis } \\
\left.\text { Temp. ( }{ }^{\circ} \mathrm{C}\right)\end{array}$} & \multicolumn{2}{|c|}{ Efluente Bruto } & \multicolumn{2}{|c|}{ Efluente Tratado } & \multicolumn{2}{|c|}{ Remoção (\%) } \\
\hline & 10 bateria & 2 20 bateria & 10 bateris & 2 20 bateria & 10 bater & o bateria \\
\hline & $13,0-17,5$ & $13,2-16,2$ & - & - & - & - \\
\hline pH & $\approx 8,5$ & $\approx 8,5$ & $\approx 4,50$ & $\approx 4,50$ & - & - \\
\hline Turbidez (NTU) & 34500 & 37667 & 209 & 141 & 99,4 & 99,6 \\
\hline AT $\left(\mathrm{mg} \mathrm{L}^{-1}\right)$ & 2090 & 2120 & - & - & - & - \\
\hline $\mathrm{SST}\left(\mathrm{mg} \mathrm{L}^{-1}\right)$ & 2777 & 2200 & 733 & 155 & 73,6 & 92,9 \\
\hline $\mathrm{SSV}\left(\mathrm{mg} \mathrm{L}^{-1}\right)$ & 2640 & 1970 & 353 & 36 & 86,6 & 98,2 \\
\hline$O \& G\left(\mathrm{mg} \mathrm{L}^{-1}\right)$ & 3660 & 3900 & 212 & 7,8 & 94,2 & 99,8 \\
\hline $\mathrm{DQO}\left(\mathrm{mg} \mathrm{L}^{-1}\right)$ & 65528 & 60300 & 4128 & 2942 & 93,7 & 95,1 \\
\hline
\end{tabular}

Vê-se que as duas baterias de ensaios apresentaram resultados de eficiência consideravelmente bons, com mais de $90 \%$ de eficiência corroborando com os resultados obtidos por Bensadok et al. (2007).

Considerando-se que as características do efluente bruto das baterias 1 e 2 são parecidas, pode-se comparar o tratamento feito na bateria 2 como mais eficiente do que o realizado na bateria 1. Verifica-se, também, pelo parâmetro DQO que, mesmo com a alta eficiência de remoção dos tratamentos, esta água não poderia ser utilizada nas torres de resfriamento, uma vez que a exigência é de $75 \mathrm{mg} \mathrm{L}^{-1} \mathrm{O}_{2}$; o alto teor de DQO na água favorece o crescimento de algas nas torres de resfriamento.

A utilização dos polieletrólitos é de grande importância na floculação a fim de deixar os flocos mais resistentes (Hami et al., 2007), porém os resultados tendem a demonstrar uma diminuição na eficiência de remoção da turbidez, ou seja, os coagulantes, quando utilizados sozinhos, apresentaram valores bem menores de turbidez do que quando associados aos polieletrólitos.

Para o tipo de efluente utilizado na pesquisa com tamanha carga orgânica, seria necessário um pós tratamento biológico, após o tratamento físico-químico e flotação por FAD, para a remoção da carga orgânica restante, que ainda é muito alta, para que se torne possível o reúso ou disposição direta nos cursos d'água.

\section{CONCLUSÕES}

1. O emprego da coagulação e floculação associado a um sistema de flotação por ar dissolvido, constitui-se em um sistema eficiente para o tratamento de efluentes com grande carga de DQO e óleos e graxas como o efluente estudado, porém é necessário outro tipo de tratamento final para que esta água possa ser reutilizada em torres de resfriamento.

2. Os coagulantes PE 019 e PC 2700 apresentaram eficiências de remoção de mais de $90 \%$ dos parâmetros estudados (turbidez, SST, SSV, SSH e DQO).

3. A faixa de pH na qual ocorre coagulação deve ser baixa e, no caso de um tratamento posterior, deve-se corrigir este $\mathrm{pH}$ com $\mathrm{NaOH}$, pois nos três casos ele foi ácido.

4. O coagulante de origem orgânica (PC 2700) apresentou maior eficiência em termos de remoção dos parâmetros estudados que os outros coagulantes.

\section{LITERATURA CITADA}

Ahmad, A. L.; Sumathi, S.; Hameed, B. H. Coagulation of residue oil and suspended solid in palm oil mill effluent by chitosan, alum and PAC. Chemical Engineering Journal, v.118, p.99-105, 2006.

Al-Shamrani, A. A.; James, A.; Xiao, H. Destabilisation of oilwater emulsions and separation by dissolved air flotation. Water Research, v.36, p.1503-1512, 2002.

Alther, G. Cleaning wastewater: removing oil from water with organoclays. Filtration+Separation. v.5, n.3 p.22-24, 2008.

Azbar, N.; Yonar, T. Comparative evaluation of a laboratory and full-scale treatment alternatives for the vegetable oil refining industry wastewater (VORW). Process Biochemistry, v.39, p.869-875, 2004.

Bensadok, K.; Belkacem, M.; Nezzal, G. Treatment of cutting oil/ water emulsion by coupling coagulation and dissolved air flotation. Desalination, v.206, p.440-448, 2007. 
Bing, L. X.; Tian, L. J.; Tian, W. Y.; Ying, W. C.; Hua, Z. X. Separation of Oil from Wastewater by Column Flotation. Journal of China University of Mining \& Technology, v.17, n.4, p.546-551, 2007.

Centurione Filho, P. L.; Di Bernardo, L. Procedimento para execução de ensaios de flotação/filtração em equipamento de bancada. Revista de Engenharia Sanitária e Ambiental, v.8, n.1, p.39-44. 2003.

Clesceri, L. S.; Greenberg, A. E. G.; Eaton, A. D. Standard methods for examination of water and wastewater . 20.ed. Washington: APHA/AWWA/WEF, 1998. 1268p.

Hami, M. L.; Al-Hashimi, M. A.; Al-Doori, M. M. Ef fect of activated carbon on BOD and COD removal in a dissolved air flotation unit treating refinery wastewater . Desalination, v.216, p.116-122, 2007.

Lelinski, D. Ash flotation of dispersed oil droplets. A model system for bitumen flotation from tar sand. Utah: Utah University, 1993. 125p. Thesis Doctorate

Willey, R. Fats, oils, and greases: The minimization and treatment of wastewaters generated from oil refining and mar garine production. Ecotoxicology and Enviromenmental Safety, v.50, p.127-133, 2001.
Yang, C. L. Electrochemical coagulation for oily water demulsification. Separation and Purification T echnology, v.54, p.388-395, 2007.

Yianatos, J. B. Fluid flow and kinetic modeling in flotation related processes. Chemical Engineering Research and Design, v.85 (A12), p.1591-1603, 2007.

Yianatos, J. B.; Henriquez, F. Boundary conditions for gas rate and bubble size at the pulp-froth interface in flotation equipment. Miner Engineering, v.20, p.625-628, 2007.

Zeng, Y.; Yang, C.; Zhang, J.; Pu, W. Feasibility investigation of oily wastewater treatment by combination of zinc and $\mathrm{P}$ AM in coagulation/flocculation. Journal of Hazardous Materials, v.147, p.991-996, 2007.

Zheng, X., Franzidis, J. P .; Johnson, N. W. An evaluation of different models of water recovery in flotation, Miner Engineering, v.19, p.871-882, 2006.

Zhi, X.; Qingzhi, F .; Weilei, Z. Research on orthogonal coagulated setting and coagulation-flotation test of tannery wastewater. Journal of Environmental Sciences, Supplement, v .21, p.S158-S161, 2009. 